
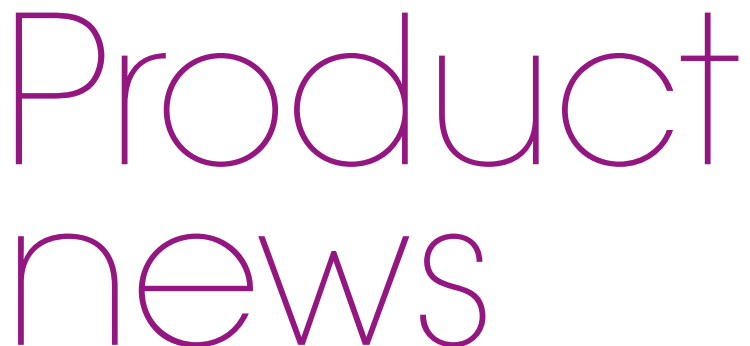

Product news is provided as a service to readers using text and images from

the manufacturer, supplier or distributor and does not imply endorsement by BDJ Team. Normal and prudent research should be exercised before purchase

or use of any product mentioned.

\title{
CLEAN, REPAIR, PROTECT AND SHINE
}

Arm \& Hammer Enamel Repair toothpaste carefully repairs and restores the enamel surface for a brighter smile in just five days.

This specially formulated daily toothpaste provides extra strengthening and makes teeth more resistant to acid erosion caused by everyday food and drink. It contains baking soda for superior cleaning power and restores enamel surface gloss when used twice a day for five days.
For stronger, brighter teeth, contact Arm \& Hammer today.

For more information about the carefully formulated Arm \& Hammer toothpaste range, visit http://www.armandhammer.co.uk/ or email ukenquiries@churchdwight.com.

Arm \& Hammer oral healthcare products are available at Boots, Superdrug, Sainsbury's, Tesco, Asda and Morrisons throughout the UK.

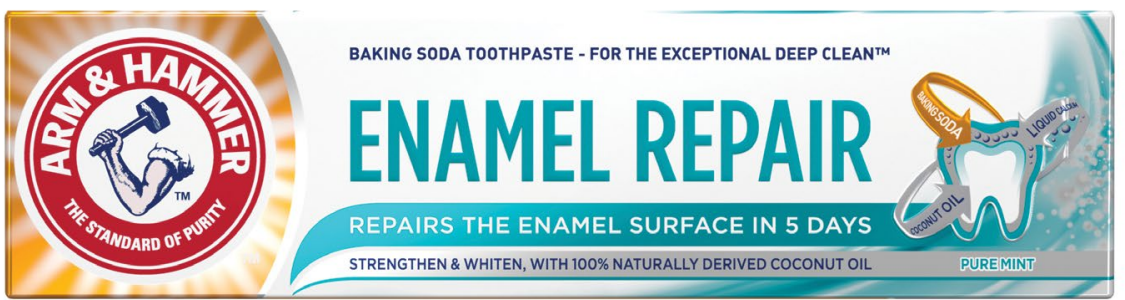

\section{TIME FOR A NEW APPROACH}

It's time for a new approach to handpiece maintenance with the Assistina TWIN. This reprocessing unit features a dual-chamber system with Quick Connect by W\&H - an innovative adaptor solution that enables you to switch effortlessly between different handpieces.

In just ten seconds, the ground-breaking oil nebulisation technology of the Assistina TWIN thoroughly lubricates the gears and cleans the spray channels of the handpiece. All aerosols produced during the process are then removed from the chamber through active suction and an integrated HEPA filter.

Combined with the Assistina TWIN Care Set, practices can benefit from an award-winning reprocessing device that makes handpiece maintenance as easy, hygienic and cost efficient as possible.

To find out more visit www.wh.com/ en_uk, call 01727874990 or email office. uk@wh.com

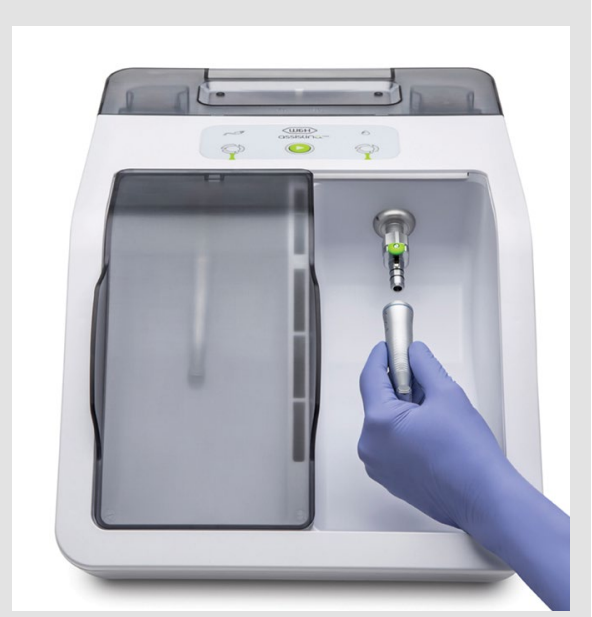

COMMUNICATION COURSE TO HELP DENTAL TEAMS SECURE SUCCESS

2020 robbed many of us of one of the most fundamental things we

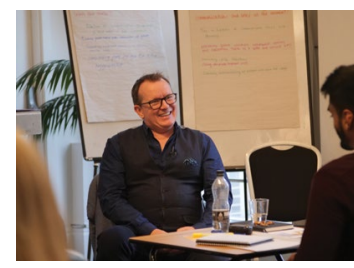

crave - human contact and connection - with lockdowns and restrictions to our daily lives having a huge impact on mental health and leaving many people feeling isolated, afraid and alone.

As we head into 2021 with yet more uncertainty ahead of us, Dr Barry Oulton (pictured), a highly experienced dentist, lecturer, trainer and businessman, is encouraging dental teams to put building rapport with their patients at the forefront.

His two-day course, Influencing Smiles, is a powerful lesson in communication and sales which teaches principal dentists and their teams how to sell with integrity and communicate with confidence.

It helps dentists boost their confidence and reduce conflict and complaints in their practices at the same time as improving their interactions with patients and boosting treatment uptake by facilitating clearer discussions around options and costs.

Upcoming events for 2021 (depending on COVID restrictions) include:

12-13 March - Birmingham

14-15 May - London

11-12 June - Birmingham

24-25 Sept - London

15-16 Oct - Birmingham.

Courses run from 9 am- 6 pm on Friday and 8 am-5 pm on Saturday.

For further details, visit www. theconfidentdentist.com, call 0333220 2447 or email sally@theconfidentdentist. com.

If you would like to promote your products or services direct to the dental industry in BDJ Team, call Andy May on 02078434785 or emaila.may@nature.com. 